\title{
Integração na criação de frangos de corte na microrregião de Viçosa - MG: viabilidade econômica e análise de risco
}

\author{
Adelson Martins Figueiredo ${ }^{1}$ \\ Pedro Antônio dos Santos ${ }^{2}$ \\ Roberto Santolin ${ }^{3}$ \\ Brício dos Santos Reis ${ }^{4}$
}

Resumo: Na microrregião de Viçosa - MG, a criação de frango de corte via contratos de integração com a PIF-PAF S/A Indústria e Comércio tornou-se fonte adicional de renda para as propriedades rurais de pequeno e médio porte. Assim, este trabalho visou verificar a viabilidade de contratos de integração nessa região; especificamente, pretendeu-se elaborar e analisar um projeto de implantação de um aviário, determinar a rentabilidade do investimento, mensurar os riscos da atividade sob o ponto de vista do integrado e auxiliar a tomada de decisão. Para isso, calcularam-se indicadores de viabilidade econômica do projeto, como Valor Presente Líquido, Taxa Interna de Retorno e Razão Benefício/Custo; além disso, foi feita uma análise de sensibilidade para posterior análise de risco. Os resultados apontaram para a viabilidade econômica do projeto; ademais constatou-se que a sua lucratividade é mais sensível aos componentes da receita do que dos custos, sendo o preço recebido por ave a variável de maior sensibilidade. Percebeu-se também que os contratos de integração não eliminam totalmente o risco da atividade e que a integradora transfere parte do risco de preços ao produtor.

\footnotetext{
${ }^{1}$ Doutorando em Economia Aplicada pelo Departamento de Economia Rural (DER) da UFV. E-mail: martinsfigueiredo@yahoo.com.br

${ }^{2}$ Doutorando em Engenharia Agrícola pelo Departamento de Engenharia Agrícola (DEA) da UFV. E-mail: pedroantoniodossantos@yahoo.com.br

${ }^{3}$ Doutorando em Economia pelo Centro de Desenvolvimento e Planejamento Regional (CEDEPLAR) da UFMG. E-mail: rsantolin@cedeplar.ufmg.br

${ }^{4}$ Professor adjunto do Departamento de Economia Rural da UFV, e-mail: bricio@ufv.br
} 
Integração na criação de frangos de corte na microrregião de Viçosa - MG:

viabilidade econômica e análise de risco

Palavras-chave: frango de corte, integração, risco, microrregião de Viçosa.

Classificação JEL: O22, L22.

Abstract: The chicken production in Viçosa area is done by integration agreement with Pif Paf Company and it is an important option for increasing the income of small farmers. The objective of this paper is to check the viability of integration agreements. A project of a plant for chicken production was drawn and observed in order to determine its profitability and risks, with the purpose of helping the decision making. The Net Present Value, Internal Rate of Return, Cost/Benefit Ratio, Risk Sensitivity and Risk Analysis were calculated. The results show that the project is feasible and the profitability is more sensitive to changes in production price than changes in production costs. This study also points out that the integration agreement does not eliminate the risk of the production, in other words, the company transfers part of the price risk to the producers.

Key words: chicken production, risk analysis, integration agreement, Viçosa area.

JEL Classification: O22, L22.

\section{Introdução}

A partir de meados da década de 1980 houve redução dos recursos governamentais destinados à agricultura brasileira. Segundo Cunha (2002), os gastos com o crédito rural no Brasil caíram de R\$29,8 bilhões em 1986 para R 8,65 bilhões em 1990. Esse ambiente de queda no volume de recursos estatais destinados às atividades agrícolas, associado à maior concorrência devido à abertura da economia, têm conduzido a um processo de tecnificação das atividades agrícolas, privilegiando as grandes propriedades agrícolas e, conseqüentemente, a agricultura comercial.

Os impactos desse processo têm se expandido pelos municípios do interior do Brasil, dificultando a manutenção de pequenas e médias pro- 
priedades rurais apenas com atividades de subsistência. Na microrregião de Viçosa, esse movimento não tem sido diferente. A alternativa para os pequenos e médios agricultores dessa região tem sido a busca de atividades que propiciem outras rendas à propriedade e, conseqüentemente, a redução dos riscos inerentes às atividades produtivas. Nos municípios da microrregião de Viçosa, a criação de frango de corte é a atividade que tem se destacado entre os produtores, sendo, especificamente, motivada pelos contratos de integração com a PIF-PAF S/A Indústria e Comércio.

Embora seja possível identificar pelo menos três sistemas de produção no setor avícola brasileiro - como o integrado, o cooperativo e o independente - o sistema que tem se tornado mais presente tanto no Brasil quanto na microrregião de Viçosa é o de integração. Isso ocorre porque a produção via contrato de integração propicia benefícios tanto ao integrador quanto ao integrado. Para o primeiro as vantagens se relacionam à redução de imobilização de capital em instalações e equipamentos, além de evitar os encargos trabalhistas. Já para o integrado as vantagens estão associadas à redução do risco da atividade, pois este consegue crédito facilitado sem a necessidade de recorrer ao sistema bancário, além de receber assistência técnica especializada e a certeza de uma renda no final da criação, sendo esta última dependente apenas de sua eficiência no manejo de cada lote (COTTA, 2003).

O sistema de integração é usado pelos produtores de frango de corte, visando elevar a renda das propriedades; conseqüentemente, tornase um instrumento que potencializa o crescimento na microrregião de Viçosa. Para esta microrregião, o sistema de integração torna-se ainda mais relevante, pelo fato de que nele o integrador fornece a ração ao integrado, sendo este insumo o mais relevante para a criação de frango de corte, uma vez que ele corresponde a, aproximadamente, 70\% dos custos de produção (COTTA, 2003). Isso se torna mais claro quando se considera a possibilidade de o próprio produtor produzir a ração em sua propriedade, visando a redução de custos, pois nessa microrregião há certa dificuldade de produção de grãos em grande escala, dadas as suas características topográficas (região montanhosa), que não são propicias à mecanização, técnica agrícola importante para produção de grãos. Assim, a produção em sistema independente possivelmente seria mais dispendiosa e arriscada do que no sistema de integração. 
Integração na criação de frangos de corte na microrregião de Viçosa - MG:

viabilidade econômica e análise de risco

Por meio dos contratos de integração, a indústria integradora, além de fornecer a ração, arca com os custos da assistência técnica, fornece e transporta os pintos de um dia, fornece medicamentos e transporta as aves adultas da granja ao abatedouro. Ao produtor integrado cabem os custos da construção do galpão e da aquisição dos equipamentos, da mão-de-obra para o manejo, da energia para iluminação, do aquecimento e ventilação do aviário e da aquisição da "cama” para forrar o piso dos aviários.

Dentre as condições para realização da integração está a disponibilidade de recursos financeiros para o investimento inicial, sendo este de interesse da indústria integradora que visa reduzir a imobilização de capital; acesso à propriedade em qualquer época do ano; ter mãode-obra permanente na propriedade; disponibilidade de água com boa qualidade e energia elétrica.

O sistema de integração possibilita o emprego da mão-de-obra familiar e apresenta baixo custo de oportunidade. Além disso, de acordo com Lopes (1992), este sistema reduz consideravelmente os riscos do integrado. Entretanto, seu rendimento é condicionado a sua eficiência no processo produtivo, cabendo ressaltar que, em geral, o conhecimento desses produtores integrados sobre a determinação de quais variáveis que, ao longo da vida útil do investimento, mais oneram seus custos é bastante reduzido, principalmente no que se refere ao uso alternativo de matérias-primas. Assim, torna-se necessário simular as condições reais desses produtores na criação de frango de corte via integração, no intuito de identificar quais variáveis mais pesam no seu orçamento e eventualmente melhor orientá-los sobre a viabilidade econômica, além de orientar possíveis produtores interessados em ingressar na atividade.

Tendo em vista a rápida expansão da demanda de carnes de frango que, conforme Gomes et al. (2003), elevou o consumo per capita de 13,5 kg a.a. em 1990 para 29,5 kg a.a. em 2001, bem como o número de pequenas e médias propriedades rurais integradas na microrregião de Viçosa, este trabalho objetivou estudar a viabilidade econômica da criação de frango de corte nessa microrregião, usando contratos de integração. Especificamente, pretendeu-se elaborar e analisar o projeto de implantação de um aviário, determinar a rentabilidade do investimento, mensurar os riscos da atividade sob o ponto de vista do integrado e auxiliar a tomada de decisão. 


\section{Metodologia}

\subsection{Métodos de avaliação econômica de projetos}

Segundo Matos (2002), as decisões sobre a viabilidade econômica de projetos de investimento resultam da estimativa e análise de indicadores de viabilidade. Dentre esses indicadores podem-se destacar o Valor Presente Líquido (VPL), a Relação Benefício/Custo (B/C), a Taxa Interna de Retorno (TIR) e o Período de Payback (PP), sendo importante salientar que a análise desses indicadores deve ser feita de maneira conjunta para auxiliar na tomada de decisão.

De acordo com Rezende e Oliveira (2001), o VPL é um dos indicadores mais utilizados na análise de viabilidade econômica de um projeto. Ele se destaca dos demais por considerar o efeito tempo e pelo fato de que os fluxos líquidos intermediários são reinvestidos à mesma taxa que representa o custo de oportunidade do capital investido pelo produtor. De acordo com Noronha (1987), o VPL pode ser representado pela seguinte equação:

$$
V P L=\sum_{t=0}^{n} \frac{L_{t}}{(1+\rho)^{t}} \text { e } t=0,1,2,3 \ldots n
$$

em que $L_{t}$ é o fluxo líquido do projeto no horizonte $n$; $\rho$ é a Taxa de Desconto (TD) relevante ou Taxa Mínima de Atratividade (TMA); e $t$ representa a variável tempo, medida em anos, ou, o horizonte de planejamento, que para esse projeto foi de 10 anos, devido ao período de recuperação dos investimentos na criação integrada de frango de corte, geralmente se efetivar entre o quinto e décimo ano.

Se o projeto apresentar um $V P L>0$, deve-se aceitá-lo como viável, pois isso indica que o valor do projeto de investimento hoje é maior do que o valor do investimento inicial, considerando o custo de oportunidade do produtor.

A TIR também é um indicador importante, por permitir que o produtor possa comparar a rentabilidade do seu projeto com a de outras atividades ligadas à agricultura ou com atividades do mercado financeiro, como investimentos em títulos públicos e/ou fundos de renda fixa. Segundo Rezende e Oliveira (2001), a TIR pode ser definida como 
Integração na criação de frangos de corte na microrregião de Viçosa - MG:

viabilidade econômica e análise de risco

a taxa de desconto (I), real e não negativa, para a qual o VPL se torna nulo, isto é:

$$
V P L=\sum_{t=0}^{n} \frac{L_{t}}{(1+I)^{t}}=0 \text { e } t=0,1,2,3 \ldots n
$$

em que (I) é a taxa interna de retorno. As demais variáveis já foram definidas. Se a TIR for maior que a TMA correspondente à taxa de remuneração alternativa do capital, o projeto será viável do ponto de vista econômico.

A razão B/C é outro indicador utilizado. Ela pode ser mensurada pela razão entre o valor atual das entradas e o das saídas, sendo representada pela equação (3):

$$
B / C=\frac{\sum_{t=1}^{n} B_{t} /(1+\rho)^{t}}{C_{0}+\sum_{t=1}^{n} C_{t} /(1+\rho)^{t}}
$$

em que $B_{t}$ são os fluxos de entrada descontados; $C_{0}$ é o investimento inicial; $C_{t}$ são os fluxos de saídas descontados; e as demais variáveis já foram definidas. Se a razão B/C for superior a 1 , conseqüentemente o projeto é viável, pois o fluxo de entradas descontado é maior do que o fluxo de saídas descontado considerando o custo de oportunidade do capital, ou seja, o VPL é positivo. Caso B/C seja inferior a 1, o projeto será inviável, ou seja, o VPL é negativo (WOILER e MATHIAS, 1996).

Segundo Rezende e Oliveira (2001), o período de payback é calculado com o intuito de verificar o espaço de tempo necessário para que os recursos investidos sejam recuperados. Não há uma definição previamente definida do tempo necessário para que isso ocorra; quanto mais rápido os recursos investidos forem recuperados, mais conveniente ou mais viável economicamente é o projeto. Entretanto, sabe-se que todo e qualquer projeto necessita de um período para recuperação do investimento inicial, sendo esse período variável de atividade para atividade. Ferreira Jr. e Baptista (2003) argumentam que, considerando um horizonte de $k$ perídos, pode-se obter o payback descontado de um projeto por: 


$$
\boldsymbol{P}=k, \text { tal que } \sum_{\mathrm{t}=0}^{\mathrm{k}}\left[\mathrm{L}_{\mathrm{t}} /(1+\rho)^{t}\right] \geq 0 \text { e } \sum_{\mathrm{t}=0}^{\mathrm{k}-1}\left[\mathrm{~L}_{\mathrm{t}} /(1+\rho)^{t}\right]<0
$$

Esse indicador pode ser tido como uma medida da liquidez e do nível de risco do projeto, uma vez que, quanto maior o tempo de recuperação do investimento, maior é o risco para o produtor.

Outros indicadores podem ser usados para a análise e avaliação de projetos de investimento. Woiler e Mathias (1996) destacam que outros indicadores, como de rentabilidade, lucratividade e ponto de equilíbrio, podem ser úteis para se verificar a viabilidade de um projeto. Considerando a incerteza e os riscos naturalmente associados à implantação de um investimento, torna-se importante reunir um conjunto de técnicas de análise e avaliação de projetos para auxiliar a tomada de decisão; assim, técnicas mais sofisticadas, como análise do ponto de equilíbrio, análises de sensibilidade e de risco, são sempre importantes para a tomada de decisão.

\subsubsection{Análise de risco e incerteza}

Dada a incapacidade de coletar todas as informações pertinentes à realização de um investimento, o risco passa a ser parte integrante do processo de realização deste; por isso, as decisões devem ser tomadas sob considerável grau de incerteza. Segundo Woiler e Mathias (1996), o risco é inerente à própria vida, sendo, portanto, impossível eliminá-lo por completo. O risco em uma atividade ocorre quando há possibilidade de que ocorram variações no estado futuro de variáveis relevantes (como preço do produto, preço e quantidade dos insumos de produção) que, conseqüentemente, afetem o retorno esperado do investimento. Entretanto, diz-se que há risco em uma atividade quando são conhecidos os possíveis valores assumidos por certa variável relevante e suas respectivas probabilidades de ocorrência. Quando as probabilidades de ocorrência e/ou, estados futuros da variável não são conhecidos, diz-se que há incerteza.

De acordo com Noronha (1987), a análise de risco é feita através da associação de probabilidades de ocorrência a uma ou mais variáveis do projeto, de maneira a estabelecer suas distribuições de probabilidades. Uma vez modelada a distribuição de probabilidade das variáveis rele- 
- Integração na criação de frangos de corte na microrregião de Viçosa - MG:

viabilidade econômica e análise de risco

vantes do projeto, geralmente, identificadas pela análise de sensibilidade, basta simular valores dessas variáveis e verificar seus impactos nos indicadores escolhidos (como o VPL, a TIR, a razão B/C, entre outros). Esses resultados são importantes para a tomada de decisão.

Em muitos casos não se tem uma série histórica que permita formular uma tabela de freqüência dos componentes do fluxo de caixa do projeto. Quando isso ocorre, podem-se usar diversas técnicas, como a Delphi e o painel de especialistas. Outra possibilidade é obter um valor mínimo, médio e máximo para a variável componente do fluxo de caixa, pois daí pode-se associar a distribuição dessa variável à função de distribuição triangular.

Nesse projeto de criação de frango de corte na microrregião de Viçosa (MG) foi possível fazer uma análise do risco associado às seguintes variáveis: preço recebido por ave entregue à PIF-PAF S/A, preço da cama de frango e preço do insumo gás. As duas primeiras são componentes da receita do produtor e a última é um componente dos custos variáveis. Para todas as variáveis a distribuição de probabilidade utilizada foi a triangular. Os valores foram extraídos de Carneiro et al. (2004) e de notas de pagamentos da PIF-PAF S/A.

\subsection{Fonte dos dados}

Nas estimativas dos custos de construção usou-se a lista de preços dos materiais de construção obtida no Departamento de Engenharia Agrícola e Ambiental da Universidade Federal de Viçosa (UFV), na planilha Obras \& Custos de 2004. Os dados do orçamento dos equipamentos necessários foram obtidos em Carneiro et al. (2004). Os dados referentes à remuneração dos integrados foram obtidos dos integrados da microrregião de Viçosa - MG.

\section{Resultados e Discussão}

\subsection{Formação do fluxo de caixa}

\subsubsection{Investimento inicial}

Depois de levantados todos os materiais necessários para a construção de dois galpões com tamanho de 12 x 125 m, foram estima- 
dos os custos dos materiais, que somam um total de aproximadamente 154,8 mil reais. Além disso, foram pesquisados também os custos dos equipamentos necessários para criação de frango de corte, como silos, comedouros, sistemas de aquecimento e outros. Esses equipamentos somaram um total de 69,4 mil reais.

\subsubsection{Composição da receita}

A formação da receita do projeto foi feita de acordo com as normas de pagamento da integradora PIF-PAF S/A Ind. e Comércio. A média de preços pagos foi de $\mathrm{R} \$ 0,22$ por cabeça de frango produzido, ressaltando que essa média é estipulada pela indústria, de acordo com os resultados obtidos do Índice de Eficiência de Produção. Para este projeto, considerou-se que, das 300 mil cabeças criadas anualmente, são entregues cerca de 285 mil, estimando uma mortalidade de $5 \%$, o que equivale a uma viabilidade ou taxa de sobrevivência de $95 \%$. Destaca-se que, Carneiro et al. (2004) apresentam um índice de viabilidade de 96,5\% como referência para análise da produção de frango de produtores familiares do Paraná. Dentre os principais índices utilizados para cálculos da receita dos integrados da PIF-PAF S/A estão os de conversão alimentar (CA), de eficiência alimentar (EA), de ganho de peso médio diário (GPD) e a viabilidade ou taxa de sobrevivência (TS). A partir desses índices podese calcular o índice de eficiência de produção (IEP), o qual é usado para remuneração do produtor a cada lote de aves entregue à integradora.

O índice de conversão alimentar mostra a eficácia da transformação de ração em peso vivo de frango, de maneira que esse indicador pode ser calculado pela seguinte razão:

$$
C A=\frac{\text { Média de consumo }(\mathrm{kg}) \text { por ave }}{\text { Média de peso vivo }(\mathrm{kg}) \text { por ave }}
$$

A eficiência alimentar é definida como o inverso da conversão alimentar, podendo-se escrevê-la pela fórmula:

$$
E A=\frac{1}{\mathrm{CA}}
$$

O ganho de peso médio diário pode ser escrito como: 


$$
G P D=\frac{\text { Peso }(\mathrm{kg}) \text { do total de aves }}{\text { Número de aves } \mathrm{X} \text { dias de idade }} \text { (7) }
$$

Sabendo-se que a taxa de sobrevivência é igual ao percentual de frangos vivos no final de cada lote, sendo obtida da razão entre o número de aves entregue ao abatedouro e o número de pintos de um dia alojados nos galpões, no início da criação do lote, o índice de eficiência de produção pode ser calculado pela seguinte fórmula:

$$
I E P=G P D \times \mathrm{TS} \times \mathrm{EA} \times 100(8)
$$

Segundo Carneiro et al. (2004), esse indicador permite classificar a eficiência do integrado conforme apresentado na Tabela 1.

Tabela 1 - Classificação dos integrados conforme a eficiência

\begin{tabular}{l|c|c|c|c|c}
\hline IEP $<200$ & $200<$ IEP $<220$ & $220<$ IEP $<230$ & $230<$ IEP $<240$ & $240<$ IEP $<250$ & IEP $>250$ \\
\hline Péssimo & Ruim & Regular & Bom & Ótimo & Excelente \\
\hline
\end{tabular}

Fonte: Carneiro et al. (2004).

De acordo com essas classificações, calculou-se a remuneração do integrado. Assim, quanto maior for sua eficiência, maior será o prêmio recebido por ele na entrega do lote à integradora.

A cama de frango também entra no fluxo de caixa como uma receita do integrado, sendo sua comercialização realizada na própria região, junto aos produtores de hortifrutigranjeiros, que usam-na como matéria orgânica para adubação. O preço médio é de aproximadamente $\mathrm{R}$ \$ 65,00 por tonelada.

\subsubsection{Custos variáveis}

Para o cálculo dos custos operacionais do aviário, Carneiro et al. (2004) sugerem o uso dos valores da Tabela 2. Esta tabela contém as parcelas dos principais custos variáveis em relação aos custos variáveis totais. Assim, basta que se conheçam os custos variáveis totais para se estimar o percentual referente a cada insumo utilizado pelo integrado. 
Tabela 2 - Participação média dos principais insumos usados na criação de frango sobre os custos variáveis totais

\begin{tabular}{|c|c|}
\hline 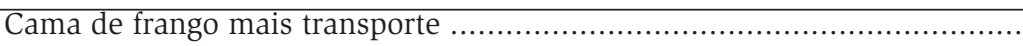 & $20 \%$ \\
\hline Gás.. & $50 \%$ \\
\hline Energia elétrica............................ & $5 \%$ \\
\hline Diaristas (mão-de-obra contratada). & $15 \%$ \\
\hline INSS. & $6 \%$ \\
\hline Outros. & $4 \%$ \\
\hline
\end{tabular}

Fonte: Carneiro et al. (2004).

\subsubsection{Depreciação anual}

No cálculo da depreciação dos galpões e dos equipamentos considerou-se a vida útil média de 30 anos para os galpões, por não haver madeiras em suas construções, e a vida útil de 10 anos para os equipamentos. Assim, para um horizonte de análise de 10 anos, o valor residual dos equipamentos é zero. Já para as construções estimou-se um valor residual de, aproximadamente, 103,2 mil reais.

\subsubsection{Taxa mínima de atratividade (TMA)}

Para definir a TMA considerou-se como custo do capital próprio a média da taxa de juros básica da economia (Over Selic) entre os anos de 1999 e 2004, que foi de 18,5\% a.a. Já para o custo do capital de terceiros considerou-se a taxa de juros média de $8 \%$ a.a., cobrada pelo Banco de Desenvolvimento de Minas Gerais (BDMG) para empréstimos a produtores rurais e pró-indústria. Essa taxa de mercado foi utilizada em substituição à taxa cobrada por financiamentos junto à integradora. Isso se justifica pelo fato de que muitos contratos de investimento em criação de frango da região em estudo, para pequenos e médios produtores, são feitos mediante financiamento da PIF-PAF S/A, embora não tenha sido possível a obtenção do custo desse financiamento. Dessa maneira, considerando que, aproximadamente, $33 \%$ e $67 \%$ do investimento total foram, respectivamente, as parcelas de capital próprio e de terceiros, calculou-se o custo médio ponderado de $11,47 \%$ a.a., que foi efetivamente considerado como o custo de oportunidade do projeto. 
Integração na criação de frangos de corte na microrregião de Viçosa - MG:

viabilidade econômica e análise de risco

Os demais resultados são apresentados na seguinte seqüência: a) análise de indicadores considerando os valores do fluxo de caixa como certos, sendo, portanto, uma análise de natureza determinista; b) análise de sensibilidade e análise de risco considerando distribuição de probabilidade triangular.

\subsection{Análise dos indicadores determinísticos}

Considerando uma taxa mínima de atratividade de $11,47 \%$ a.a., calculou-se o VPL do projeto de investimento na produção de frango de corte na microrregião de Viçosa, conforme formulação apresentada na equação (1). O VPL calculado foi positivo e apresentou um valor de $\mathrm{R} \$ 17.508,57$, indicando a viabilidade do investimento. Assim, pode-se dizer que, ainda que os fluxos líquidos de cada período fossem aplicados a uma taxa de 11,47\% a.a., o valor da empresa ainda seria aumentado em cerca de $\mathrm{R} \$ 17,5$ mil.

Por meio da equação (2), calculou-se a TIR do projeto, que apresentou valor de $16,26 \%$ a.a., sendo, portanto, maior que o custo de oportunidade considerado, de $11,47 \%$ a.a. Assim, como o VPL, a TIR indica a viabilidade do projeto. Neste caso, comparando-se a taxa de retorno do projeto com a taxa de rendimento da caderneta de poupança, que esteve entre $7 \%$ a.a. e $10 \%$ a.a. em 2004, o investimento proposto certamente é mais atrativo - eventualmente, desconsiderando a preferência pela liquidez. Por sua vez, caso o integrado tivesse que realizar todo o investimento inicial com capital próprio, a viabilidade dessa atividade seria questionável uma vez que a TIR calculada em 16,26\% a.a. é inferior à taxa de juros básica da economia, a qual eventualmente foi considerada como custo de oportunidade do capital próprio.

Destaca-se ainda que, no caso do sistema de integração, a firma integradora realiza operações de financiamento ao integrado, a inclusão do capital de terceiros na atividade é quase sempre certa, uma vez que, ao receber o financiamento da empresa integradora, eventualmente, os riscos associados ao investimento caem, devido à certeza de que a integradora cumprirá com sua parte no contrato. No entanto, essa operação beneficia a integradora, visto que esta também se apropria de parte dos rendimentos do produtor integrado, por meio da cobrança de juros sobre o financiamento. 
Uma outra maneira de verificar a viabilidade de um projeto é através da relação $B / C$, calculada por meio da equação (3). No caso desse empreendimento, essa relação foi superior a 1 (um), indicando que, para cada $\mathrm{R}$ \$ 1,00 investido, o integrado recebe $\mathrm{R} \$ 1,30$ ao longo da vida útil do projeto, evidenciando, nesse sentido, a viabilidade econômica do investimento.

O período de payback descontado foi estimado em 5,26 anos, indicando que o retorno do capital investido se dá em aproximadamente 5 anos e 3 meses. Esse prazo corresponde ao tempo que o avicultor tem para liquidar o capital investido e para alertá-lo sobre novas tomadas de decisão.

Nota-se que todos os critérios determinísticos utilizados para avaliar esse projeto apontaram para sua viabilidade. Entretanto, é bom lembrar que as margens de lucro desse tipo de atividade são pequenas; ademais, o volume de investimentos é razoavelmente grande exigindo um alto investimento inicial. Por isso, a atividade não tolera improvisações - qualquer erro no manejo das aves pode levar a reduções consideráveis de lucratividade.

A TIR encontrada $(16,47 \%)$ é um dos objetivos a ser perseguido, pois ela está entre a taxa de rendimento da poupança e a taxa Over Selic. Assim, qualquer instabilidade financeira da indústria integradora e/ou uma simples queda de energia que eleve o índice de mortalidade por lote de frango entregue e que, conseqüentemente, reduza o índice de eficiência IEP, poderá refletir negativamente na rentabilidade da atividade.

\subsection{Análise de risco}

Foram feitas análises de sensibilidade e identificadas as variáveis que produzem maiores instabilidades sobre o VPL e a TIR. Dentre estas variáveis foi possível fazer análise de risco sobre o preço do frango, o preço da cama de frango e os custos do insumo gás. O preço recebido pelo produtor integrado é um item de risco, pois está sujeito à eficiência no manejo, bem como a fatores climáticos e ambientais, de difícil monitoramento. O preço da cama de frango também é passível de risco, embora em menor intensidade, devido ao fato de que ela pode ser utilizada como adubo orgânico, quando não vendida para alimentação animal. Por sua vez, o preço do gás é importante de ser analisado, uma vez que há outra matéria-prima de uso alternativo: o carvão vegetal. 
Integração na criação de frangos de corte na microrregião de Viçosa - MG:

viabilidade econômica e análise de risco

Na Tabela 3 é apresentado um resumo dos resultados de variações do VPL e da TIR para 5 mil iterações, utilizando o programa @Risk 4.5 (PALISADE COPORATION, 2002). Para a entrada dos valores mínimos, médios e máximos na função de distribuição triangular, considerou-se que o consumo de gás aumentaria $15 \%$ no período mais frio do ano e reduziria $15 \%$ no período mais quente. Além disso, o repasse de $15 \%$ seria o mesmo para o custo total do insumo, que corresponde a $\mathrm{R} \$$ 15.000,00; assim, o valor mínimo considerado foi de $\mathrm{R} \$ 12.750,00$, e o máximo, de $\mathrm{R} \$ 17.250,00$. Em se tratando dos preços dos frangos, considerou-se o preço de $\mathrm{R} \$ 0,18$ por ave entregue à integradora como sendo o valor mínimo, um valor médio de $\mathrm{R} \$ 0,22$ e o valor máximo de $\mathrm{R} \$ 0,26$; cabe destacar que estes valores estão em conformidade com os estimados para os contratos de integração para os agricultores familiares do Paraná, conforme argumentam Carneiro et al. (2004).

Tabela 3 - Resultados da simulação dos possíveis valores do VPL e da TIR para a criação de frango de corte na microrregião de Viçosa via integração

\begin{tabular}{lcc}
\hline Indicadores & $\begin{array}{c}\text { Valor presente líquido } \\
\text { (VPL) }\end{array}$ & $\begin{array}{c}\text { Taxa interna de retorno } \\
\text { TIR }\end{array}$ \\
\hline Resultado máximo & 77628,25 & 0,3142 \\
Resultado médio esperado & 17508,48 & 0,1610 \\
Resultado mínimo & $-47294,57$ & $-0,0351$ \\
Chance de resultado positivo & $79,10 \%$ & $79,00 \%$ \\
Chance de resultado negativo & $20,90 \%$ & $21,00 \%$ \\
Desvio-padrão & 20982,27 & 0,0566 \\
Simulações & 5000 & 5000 \\
Iterações & 27 & 27 \\
Erros & 0 & 0 \\
\hline
\end{tabular}

Fonte: Resultados da pesquisa.

Dos resultados apresentados, percebe-se que a análise de risco foi importante, pois todos os indicadores apontavam inicialmente para a viabilidade do projeto. Todavia, considerando os resultados apresentados na Tabela 3, é possível perceber que há chances de insucesso na produção de frango de corte na microrregião de Viçosa, com probabilidade simulada de 20,9\% para um VPL negativo. Cabe destacar que a probabilidade de sucesso da atividade é efetivamente maior que a de 
insucesso, sendo seu valor estimado em $79,10 \%$, considerando-se os valores simulados do VPL, e 79,00\% para a TIR. Os valores médios do VPL e da TIR foram estimados em $\mathrm{R} \$ 17.508,48$ e $16,10 \%$, respectivamente. Dessa forma, esses resultados mostram que essa atividade não está desassociada de risco, ainda que se tenha um contrato de integração.

Para melhor ilustrar esses resultados, na Figura 1 é apresentada a distribuição de probabilidade acumulada do VPL, de maneira que se torna possível visualizar a área em que a função de distribuição aponta probabilidades exatas de 20,9025\% de chance de ocorrerem valores negativos para o VPL. Assim, é possível inferir que o produtor integrado deve estar sempre atento a sua eficiência, pois, caso contrário, há possibilidade de ocorrência de prejuízo, obviamente, em situações de muita instabilidade. Coeficientes de correlações entre o VPL e as variáveis preço do frango, preço de venda da cama de frango e custo do gás foram estimados em $0,923,0,335$ e -0,104, respectivamente, mostrando que há maior instabilidade do VPL para alterações nos componentes da receita do que para componentes dos custos. Esse resultado era esperado devido ao contrato de integração, que reduz consideravelmente os custos do integrado.

Figura 1 - Distribuição de probabilidade acumulada de ocorrência de possíveis valores do VPL, após 5 mil iterações usando o programa @Risk, para o fluxo de caixa do projeto de produção de frango de corte via integração na microrregião de Viçosa - MG.

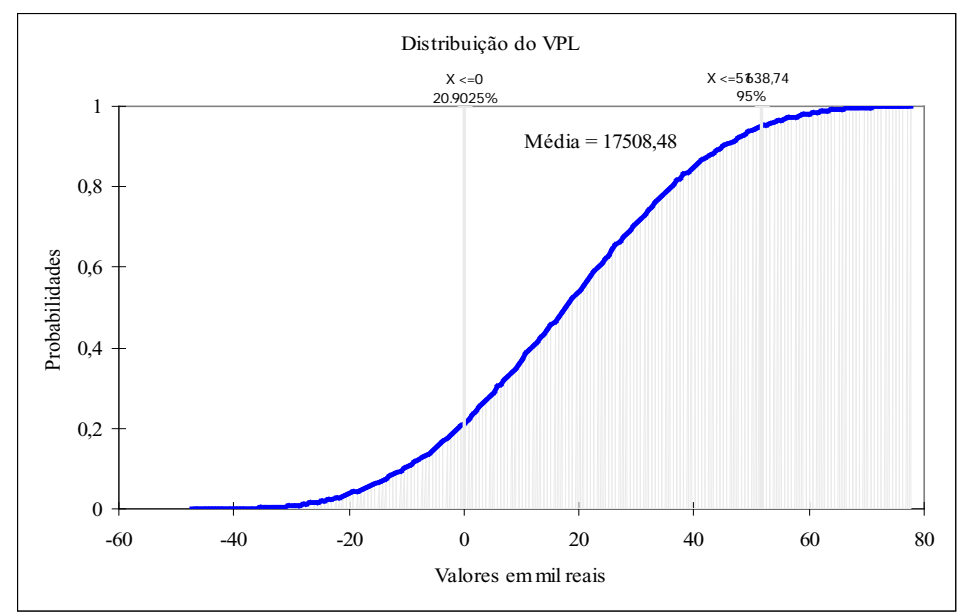

Fonte: Resultados da pesquisa. 
Integração na criação de frangos de corte na microrregião de Viçosa - MG:

viabilidade econômica e análise de risco

A Figura 2 apresenta a distribuição de probabilidade acumulada para a taxa interna de retorno. Essa figura é particularmente interessante, pois ela deixa claro que há uma probabilidade de $95 \%$ de que a TIR seja inferior a $25 \%$ a.a. Assim, destaca-se que, dependendo do perfil de risco do produtor, ele tem uma chance considerável de procurar uma outra atividade, caso queira maior retorno para o capital investido. Os coeficientes de correlação entre a TIR e as variáveis preço do frango, preço da cama de frango e custo do gás foram aproximadamente iguais aos estimados para o VPL, sendo, portanto, desnecessária sua apresentação.

Figura 2 - Distribuição de probabilidade acumulada de ocorrência de possíveis valores para a TIR, após 5 mil iterações usando o programa @Risk, para o fluxo de caixa do projeto de criação de frango de corte em sistema de integração na microrregião de Viçosa - MG.

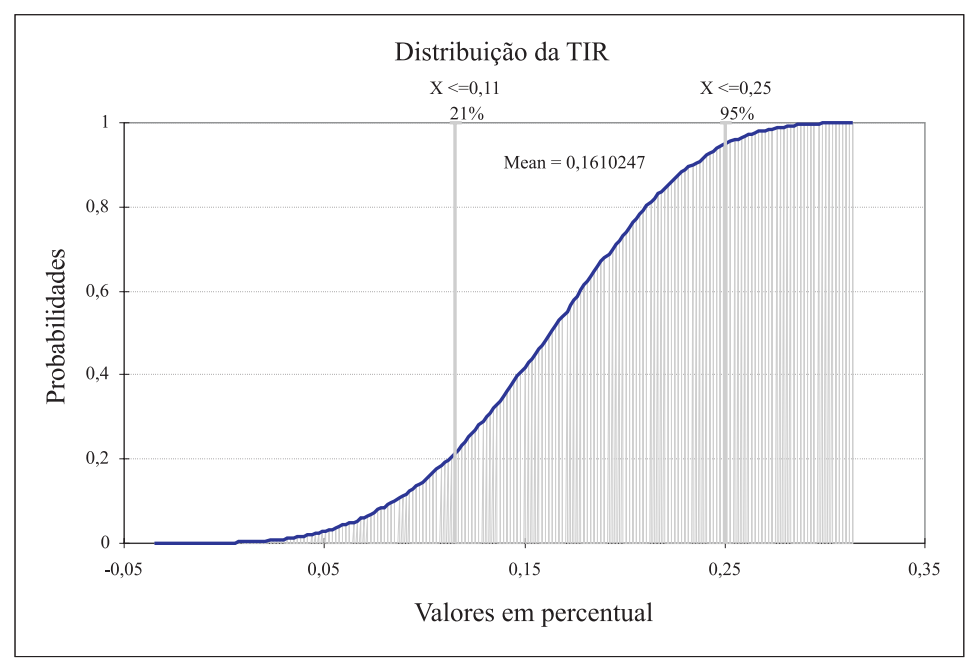

Fonte: Resultados da pesquisa.

Os resultados permitem concluir que, apesar de o contrato de integração reduzir os riscos associados ao fornecimento de matéria-prima, ele não elimina aqueles associados ao preço e a fatores ambientais. Dessa maneira, o produtor está sujeito a epidemias e falhas no manejo, que podem levar à perda de eficiência e, conseqüentemente, a reduções dos preços recebidos da integradora. 


\section{Conclusões}

A produção de frango de corte na microrregião de Viçosa é viável pelos critérios do VPL e da TIR, considerando uma taxa de desconto de $11,47 \%$ a.a. No entanto, a rentabilidade da atividade não é muito elevada: para cada real investido, o produtor tem apenas $\mathrm{R}$ 1,30 de retorno; portanto, o integrado deve estar sempre atento aos seus custos e procurar minimizar as falhas de manejo.

Os principais riscos associados a esse projeto concentraram-se nos preços recebidos da integradora, por causa da sua associação à eficiência na produção. Por isso, mais do que analisar a viabilidade, o produtor deve buscar o pleno conhecimento da produção de frango, visando maximizar o índice de eficiência de produção.

Nas análises de risco, constatou-se ainda que a atividade é passível de prejuízos. Portanto, recomenda-se ao integrado potencial que o financiamento seja feito junto à integradora, como forma de redução de riscos, pois, quando isso ocorre, espera-se que haja maior incentivo por parte da integradora para que a atividade seja bem sucedida, uma vez que algum recurso foi despendido para realização dos investimentos iniciais, isto é, o comprometimento confiável entre integrado e integradora é necessário para redução dos riscos do processo.

Por outro lado, com a integração, a integradora certamente transfere parte do risco de preços para o integrado, reduzindo sua margem de lucratividade. Isso justifica a correlação de 0,923 entre o VPL e o preço do frango entregue à integradora. Assim, a rentabilidade do integrado fica de certa maneira condicionada aos interesses da integradora; por isso, não há alternativa melhor do que ser o mais eficiente possível no processo de criação. Nesse sentido, a redução de custos com uso de matérias-primas alternativas também fica comprometida, visto que a substituição deve ser feita de forma criteriosa, para não alterar a eficiência já alcançada.

\section{Referências Bibliográficas}

CARNEIRO, S. L. et al. Redes de referências para agricultura familiar do estado do Paraná. Paraná: Londrina, 2004. [20 Jan. 2005]. (http:// www.emater.pr.gov.br/ Redesrefer/RM_AviculturaCorte_N.pdf). 
COTTA, T. Frangos de corte: criação, abate e comercialização. Viçosa: Aprenda Fácil, 2003. 237 p.

CUNHA, A.R.A.A. Mudanças institucionais e armadilhas metodológicas: uma análise comparativa dos censos agropecuários de 1985 e 1995/96 para o Estado de Minas Gerais. In: SEMINÁRIO SOBRE ECONOMIA MINEIRA, 10. 2002, Diamantina. Anais... Belo Horizonte, MG: CEDEPLAR, 2002. 1 CD-ROM.

FERREIRA JR, S.; BAPTISTA, A. J. M. S. Impactos do programa de fomento à cafeicultura no pequeno produtor do município de Viçosa - MG: uma análise financeira sob condições de risco. Revista de Economia e Agronegócio, Viçosa, v. 1, n. 4, p. 561-573, Out./Dez. 2003.

GOMES, M. T. M. et al. Decomposição dos preços de frango, suíno e bovino nos anos 80 e 90 no Brasil. In: CONGRESSO BRASILEIRO DE ECONOMIA E SOCIOLOGIA RURAL, 41. 2003 Juiz de Fora. Anais... Brasília, DF: SOBER, 2003. 1 CD-ROM.

LOPES, J. E. P. Análise econômica de contratos de integração usados no complexo agroindustrial avícola brasileiro. Viçosa, MG: UFV, 1992. 105 f. Tese (Mestrado em Economia Rural) - Universidade Federal de Viçosa, 1992.

MATOS, C. M. Viabilidade e análise de risco de projetos de irrigação: estudo de caso do Projeto Jequitaí (MG). Viçosa, MG: UFV, 2002. 142 f. Tese (Mestrado em Economia Aplicada) - Universidade Federal de Viçosa, 2002.

NORONHA, J.F. Projetos agropecuários: administração financeira, orçamento e viabilidade econômica. 2. ed. São Paulo: Editora Atlas S/A, 1987. 269 p.

PALISADE CORPORATION.@RISK 4.5 for industrial edition. New York, 2002.

REZENDE, J. L. P.; OLIVEIRA, A. D. Análise econômica e social de projetos florestais. Viçosa: Editora UFV, 2001. 389 p.

WOILER, S.; MATHIAS, W. F. Projetos: planejamento, elaboração e análise. 1. ed. São Paulo: Atlas S/A, 1996. 294 p.

Recebido em novembro de 2005 e revisto em junho de 2006. 